\title{
Analysis of energy use and carbon losses in the chemical industry
}

\author{
Maarten Neelis ${ }^{\mathrm{a}, *}$, Martin Patel ${ }^{\mathrm{a}}$, Pieter Bach ${ }^{\mathrm{b}}$, Kornelis Blok ${ }^{\mathrm{a}}$ \\ ${ }^{a}$ Utrecht University, Copernicus Institute, Department of Science, Technology and Society, \\ Heidelberglaan 2, 3584 CS Utrecht, The Netherlands \\ ${ }^{\mathrm{b}}$ Energy Research Centre of The Netherlands, Unit Energy Efficiency in Industry, Westerduinweg 3, \\ 1755 LE Petten, The Netherlands
}

Available online 26 March 2007

\begin{abstract}
A preliminary bottom-up analysis of the energy use in the chemical industry has been performed, using a model containing datasets on production processes for 52 of the most important bulk chemicals as well as production volumes for these chemicals. The processes analysed are shown to cover between $70 \%$ and $100 \%$ of the total energy use in the chemical sector. Energy use and the heat effects of the reactions taking place are separately quantified. The processes are also compared with energetically-ideal processes following the stoichometric reactions. The comparison shows that there is significant room for process improvements, both in the direction of more selective processes and in the direction of further energy-savings.
\end{abstract}

(c) 2007 Elsevier Ltd. All rights reserved.

Keywords: Chemical industry; Energy use; $\mathrm{CO}_{2}$ emissions; Energy efficiency; Selectivity

\section{Introduction and purpose}

Numerous studies describing the structure of energy use in the chemical industry are available from the open literature. Some studies aim to determine life-cycle energy-use and $\mathrm{CO}_{2}$ emission data for intermediates and plastics [1-3], while other studies aim to give an overview of the chemical sector for a given region [4-7]. Yet other studies aim to

\footnotetext{
* Corresponding author. Tel.: +31 30 2537600; fax: +31 302537601.

E-mail address: m.1.neelis@chem.uu.nl (M. Neelis).
} 
describe Best Available Technologies [8] or to define potentials for process improvement [9-11]. The studies differ widely in geographical scope and in completeness, key assumptions and aggregation level. The underlying data for all the studies are dispersed and it is difficult to use them directly for bottom-up analyses of energy use and $\mathrm{CO}_{2}$ emissions in the chemical industry for various regional boundaries and for various levels of aggregation. We therefore developed a model, containing a variety of datasets on production processes for 52 of the most important bulk chemicals in terms of production volume. The model also contains production volumes for those chemicals and shares of individual process routes in three geographical regions: The Netherlands, Western Europe ${ }^{1}$ and the World. The model facilitates making detailed bottom-up analyses of energy use and $\mathrm{CO}_{2}$ emissions both at the level of individual processes and at the level of the chemical sector as a whole for the three regions included. In this paper, we give some preliminary results of such an analysis in which we focus on energy use, with minor attention to $\mathrm{CO}_{2}$ emissions. Questions that will be answered are (a) how is the energy use in the chemical sector distributed over the various processes and especially (b) what are the main components of energy use and $\mathrm{CO}_{2}$ emission in the chemical industry (e.g. energy use versus reaction losses)?

\section{Scope methodology and data sources}

The model contains datasets for 73 different production processes ${ }^{2}$ for 52 of the most important organic bulk-chemicals ${ }^{3}$ in terms of production volume. For each of those chemicals, we included:

- The production volume in The Netherlands, Western Europe and the World.

- The share of the various production processes in these three regions, if the chemical can be made via more than one production route.

- The heat and Gibbs free-energy of reaction of the stoichometric reaction, thereby allowing a comparison between the actual process and the ideal process.

For the 73 process routes, a total of 250 datasets is included in the model. The key data as found in the literature are complemented with background data on the carbon content, the calorific value and the price of raw materials, products and energy commodities used. Most datasets were taken from the open literature sources like [12-14], complemented with some confidential datasets available to the authors. The two most important data sources for the production data and for the shares of the various process routes have been $[15,16]$. In cases where we did not have production data, we used capacity data instead. The most recent production data were used and no production data older than the mid 1990s was used. A major difficulty is the incomparability of the various datasets from the literature. Some sources refer explicitly to current Best Available Technologies, whereas other sources give data for the European average in a given year. For the analyses shown in Section 3 of this paper, we have chosen the dataset, which most likely represents the average

\footnotetext{
${ }^{1}$ Defined as the European Union (15 countries) and Norway and Switzerland.

${ }^{2}$ Some chemicals can be made from various raw materials, which explains the number of process routes to be larger than the number of chemicals.

${ }^{3}$ Complemented with chlorine and ammonia.
} 


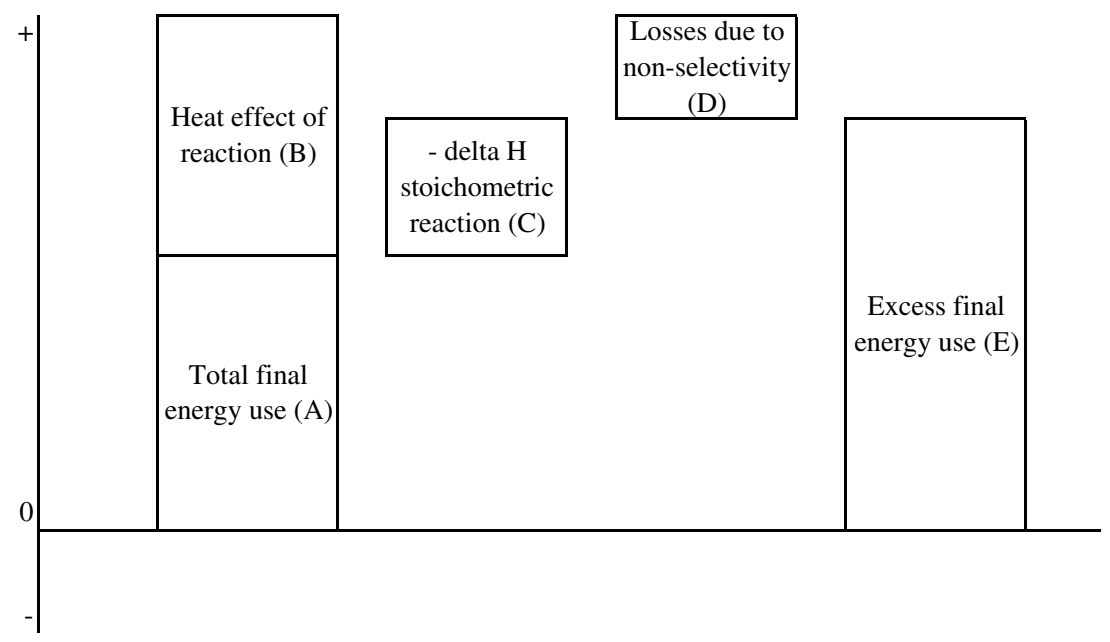

Fig. 1. Overview and definition of energy-related indicators.

technology in use in Western Europe nowadays in cases where more than one dataset was available; this choice was based on our own judgements. For process routes only applied outside Europe, we took the average technology in place in the World. For the most energy-consuming processes (olefins and ammonia production, covering more than $50 \%$ of the energy use in the chemical industry), several datasets were available, which allowed determining these average technologies with sufficient accuracy. In cases where only one process dataset was available, we used this dataset in the analysis. It should be emphasised that the process datasets are mainly from the open literature and are not based on manufacturing experience in highly energy-integrated plant sites. These and other uncertainties will be addressed in Section 6.

The model allows calculating various indicators relevant with respect to energy efficiency, process related $\mathrm{CO}_{2}$ emissions, waste flows and process profitability for each of the datasets included. In this paper we focus on the indicators related to energy. An overview is given in Fig. 1. For each dataset, we define:

A: The total final energy-use as the sum of fuel, steam ${ }^{4}$ and electricity use in the process. Most processes consume energy $(\mathrm{A}>0)$, but exothermic reaction can also be net energy exporters $(\mathrm{A}<0)$.

$B$ : The heat effect of reaction as the difference between calorific value of raw materials and products. For an exothermic reaction, which is shown in Fig. 1, B $>0$ and for an endothermic reaction $\mathrm{B}<0$.

$\mathrm{C}$ : The negative value of the heat of reaction of the stoichometric desired reaction. For an exothermic reaction, $\mathrm{C}>0$ and for an endothermic reaction, $\mathrm{C}<0$.

\footnotetext{
${ }^{4}$ We distinguished between low-pressure steam $(2.8 \mathrm{GJ} /$ ton $)$, middle-pressure steam $(3.0 \mathrm{GJ} /$ ton $)$ and highpressure steam $(3.2 \mathrm{GJ} / \mathrm{ton})$ and used middle pressure steam-properties when no specification was given in the literature source.
} 
Table 1

Comparison of datasets with energy statistics for AD 2000

\begin{tabular}{|c|c|c|c|c|c|}
\hline & Datasets PJ & Energy statistics 2000, PJ & Coverage $(\%)$ & Indicator A + B & PJ \\
\hline \multicolumn{6}{|l|}{ The Netherlands } \\
\hline Electricity & 17 & 43 & 39 & A & 17 \\
\hline Fuels $^{\mathrm{a}}$ & 214 & 182 & 118 & A & 214 \\
\hline Feedstock $^{\mathrm{a}}$ & 295 & 306 & 96 & & \\
\hline Heat effect of reaction & & - & - & B & 30 \\
\hline Total & 526 & 531 & 99 & & 261 \\
\hline \multicolumn{6}{|l|}{ Western Europe } \\
\hline Electricity & 190 & 674 & 28 & A & 190 \\
\hline Fuels $^{\mathrm{a}}$ & 989 & 1,394 & 71 & A & 1177 \\
\hline Feedstock $^{\mathrm{a}}$ & 2,257 & 2,752 & 82 & & \\
\hline Heat effect of reaction & & - & - & B & 84 \\
\hline Total & 3,435 & 4,821 & 71 & & 1,451 \\
\hline \multicolumn{6}{|l|}{ World } \\
\hline Electricity & 865 & 3131 & 28 & A & 865 \\
\hline Fuels $^{\mathrm{a}}$ & 4,454 & 10,349 & 43 & A & 6,762 \\
\hline Feedstock $^{\mathrm{a}}$ & 13,625 & 14,414 & 95 & & \\
\hline Heat effect of reaction & & - & - & B & 359 \\
\hline Total & 18,944 & 27,894 & 68 & & 7,986 \\
\hline
\end{tabular}

${ }^{\text {a }}$ The allocation method between fuel use and feedstock use is explained in the text.

In an ideal process from an energy point of view, the total final energy use would be exactly the negative of the heat of reaction $(A=-C)$, since all energy that becomes available in an exothermic reaction would be recovered (e.g. in the form of steam) and exported from the process or exactly the amount of final energy that is required in an endothermic reaction would be used in the process ${ }^{5}$.

In the comparison with the heat of the stoichometric reaction (indicator $\mathrm{C}$ ), we therefore define two indicators:

D: The losses resulting from non-selectivity of the reaction is defined as the difference between the heat effect of reaction and the stoichometric heat of reaction (indicator $\mathrm{B}-\mathrm{C}$ ). The losses due to non-selectivity are always equal or larger than zero.

E: The excess final energy use defined as the difference between the total final energy use and the ideal final energy-use $(\mathrm{A}-\mathrm{C}=\mathrm{A}+\mathrm{C})$.

\section{Results}

\subsection{Total bottom-up analysis of the energy use in the chemical industry}

By adding up the absolute energy-use (in PJ) for all process routes included, a bottomup estimate can be made of the total energy-use in the chemical industry. By comparison

\footnotetext{
${ }^{5}$ These statements are based on the first law of thermodynamics and do not consider losses in quality of energy like for example in exergy analysis. In practice, a significant part of the heat of reaction becomes available as waste heat at low temperatures and can therefore not be utilised.
} 
with the total energy use according to energy statistics [17], the energy coverage of the process routes can be determined and the consistency can be checked. We present such a comparison in Table 1.

The comparison is complicated by the inconsistencies with respect to the definition of feedstock use in the international energy statistics. In some countries feedstock use is defined as the total raw-material input to processes where fuels are converted to chemicals (e.g. the extraction of aromatics, steam cracking to produce olefins and steam reforming to produce ammonia and methanol), whereas in other countries, the input is split into a part used as feedstock and a part used as fuel. These issues are currently being studied in a research project financed by the European Commission [18]. The insight gained in this project has been taken into account in the first four columns of Table 1, thereby ensuring consistency with the methodology chosen in the energy statistics:

- For The Netherlands, we know that the fuel use in steam reforming (methanol and ammonia) is allocated to fuel use rather than to feedstock use. The fuels use in those processes is defined as the difference between raw material input and product output. The basic aromatics are considered as energy commodities and therefore only the conversion of these aromatics to their derivatives is reported as feedstock use. The feedstock use of the steam crackers is calculated by deducting the fuels produced from the total input to the steam crackers.

- For Western Europe and the World, the allocation method is not known. We assumed the total input to ammonia and methanol production to be allocated to feedstock use as well as the calorific value of the basic aromatics. For steam cracking, we assumed the same allocation method as applied in The Netherlands.

- For the calculation of indicators A and B (last column), we did allocate the fuel use in ammonia and methanol production fuel rather than to feedstock use, which is for Western Europe and the World in contradiction with the method applied in the comparison with the energy statistics (first four columns).

The comparison has several shortcomings (see also Section 6) like:

- The use of capacity data rather than production data for some of the chemicals (this might explain the high coverage for The Netherlands).

- The employment of energy-use data for average Western Europe processes instead of correcting for regional differences in energy efficiency.

- The lack of knowledge about feedstock allocation in worldwide energy-statistics.

In spite of these shortcomings, we can still conclude that the production of the 52 chemicals included cover a significant part ( $\sim 75 \%$ for Western Europe) of the fuel and feedstock demand in the chemical sector. The coverage of electricity use is much lower $(\sim 30 \%)$. This can be explained partly by the fact that some major electricity-consumers (air separation, phosphor and silicon carbide production) are not included and partly by the fact that more downstream small volume products that are not included tend to be more electricity and less fuel intensive. The distribution of the sum of the total final energy use and the heat effect of reaction over the 73 processes included is shown in Fig. 2 and the division between heat effect of reaction and final energy use is shown in Fig. 3. 


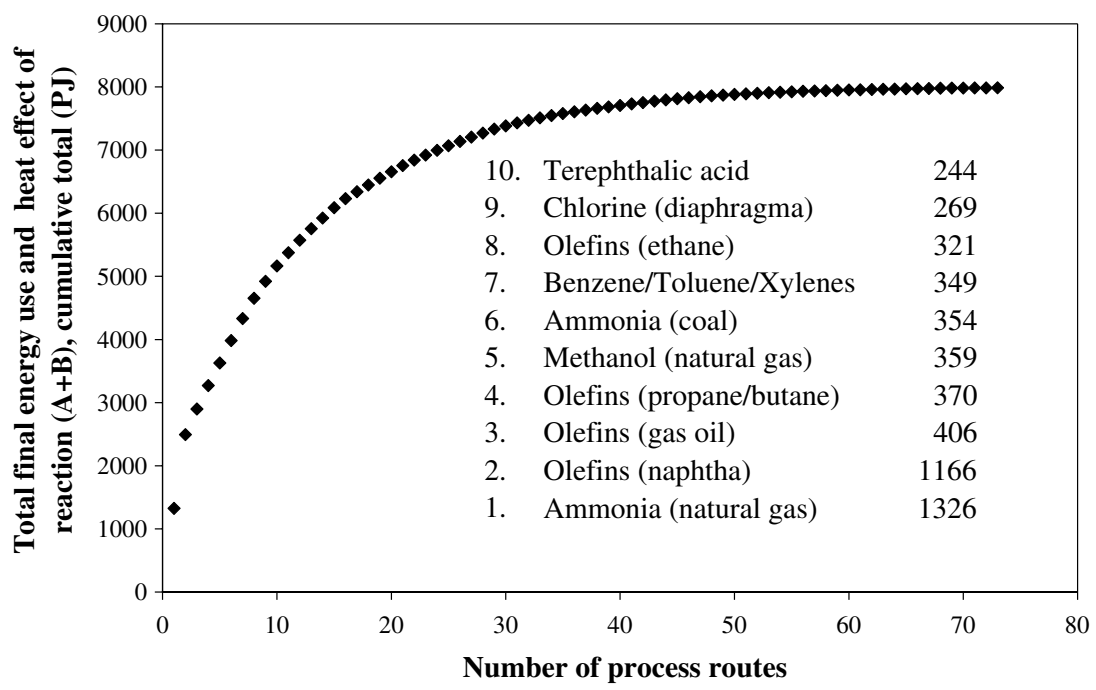

Fig. 2. Distribution of the sum of total final energy-use (A) and heat effect of reaction (B) worldwide over the 73 processes included.

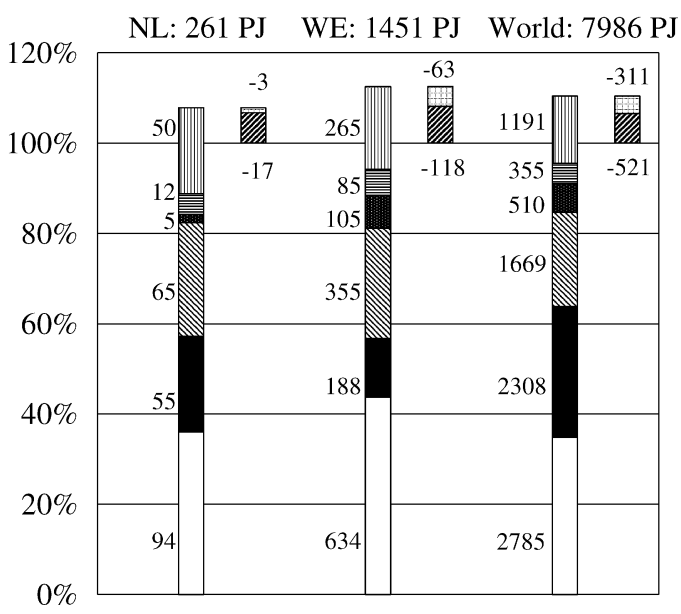

\begin{tabular}{|c|}
\hline $\begin{array}{l}\text { Endothermicity chlorine } \\
\text { production }\end{array}$ \\
\hline $\begin{array}{l}\mathbb{E} \text { Endothermicity olefin } \\
\text { production }\end{array}$ \\
\hline $\begin{array}{l}\text { Cumulative exothermicity } \\
\text { other processes }\end{array}$ \\
\hline $\begin{array}{l}\text { Electricity use, other } \\
\text { processes }\end{array}$ \\
\hline $\begin{array}{l}\text { Electricity use, chlorine } \\
\text { production }\end{array}$ \\
\hline $\begin{array}{l}\mathbb{N} \text { Fuel/Steam use other } \\
\text { processes }\end{array}$ \\
\hline $\begin{array}{l}\text { Fuel use ammonia and } \\
\text { methanol production }\end{array}$ \\
\hline$\square$ Fuel use olefin production \\
\hline
\end{tabular}

Fig. 3. Division of heat effect of reaction and total final energy-use.

Figs. 2 and 3 clearly show the major contributions olefin production $(\sim 35 \%)$ and ammonia and methanol production ( $29 \%$ worldwide, $21 \%$ in The Netherlands and $13 \%$ in Western Europe) to the sum of total final energy-use and the heat effects of reaction. The top 10 processes listed in Fig. 2 already account for $65 \%$ of the total and the top 30 already for $92 \%$ of the total of the 73 process routes included. Fig. 3 shows that in steam cracking to produce olefins and in chlorine production, part of the energy is used to drive the endothermic cracking reactions and is therefore converted to chemical energy. In the remainder of the chemical industry, the conversions are mainly exothermic ${ }^{6}$ and the total cumulative

\footnotetext{
${ }^{6}$ Some dehydrogenation reactions like the conversion from ethylbenzene to styrene are exceptions.
} 


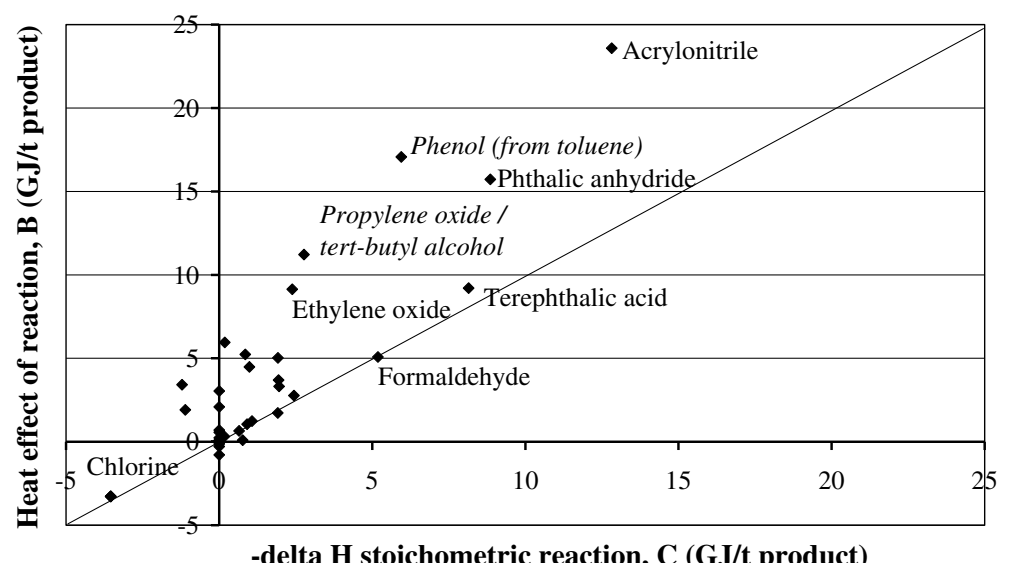

Fig. 4. Heat effect of reaction (B) as a function of stoichometric heat of reaction (C) for processes applied in The Netherlands (points in italics are based on older sources and might be overestimations).

exothermicity (excluding olefin and chlorine production) is substantial (1191 PJ worldwide).

\section{Results for individual processes}

In Fig. 4, we further explore this exothermicity for the processes applied in The Netherlands by plotting the heat-effect of reaction (indicator B) as a function of the negative of the heat of the stoichometric reaction (indicator C). Not surprisingly, the heat effect of reaction is largest in oxidation processes. The vertical distance between the data points and the diagonal line is a measure for the energy losses due to non-selectivity (indicator D). Some processes approach 100\% selectivity (e.g. chlorine, formaldehyde and terephthalic acid), whereas others (e.g. acrylonitrile and ethylene oxide) are rather unselective $^{7}$. The potentials for improvements in process selectivity are substantial in those processes. We calculated the energy loss from non-selectivity to be approximately $50 \%$ ( $\sim 500$ PJ worldwide) of the total exothermic heat-effect of reaction, excluding the endothermic steam-cracking and chlorine-production processes.

Losses due to non-selectivity can either be caused by over-oxidation of the feedstock (e.g. in ethylene-oxide production) or from the formation of non-valuable fuel grade by-products, also referred to as off-specs (e.g. in the combined production of propylene oxide and styrene). In the first case, the energy becomes available as process heat and might be recovered and used in the process itself or exported to be used in other processes. This energy recovery results in a lower use of energy or even in a net export of energy (e.g. steam). In the second case, the off-specs can be burned and part of the energy can be regenerated. Whereas the first type of energy recovery is most likely netted off in the energy data found in the process description from the literature, this is somewhat unclear for the sec-

\footnotetext{
${ }^{7}$ Data points under the diagonal line are caused by small errors (e.g. a reported molar yield above unity) in the data sources used.
} 


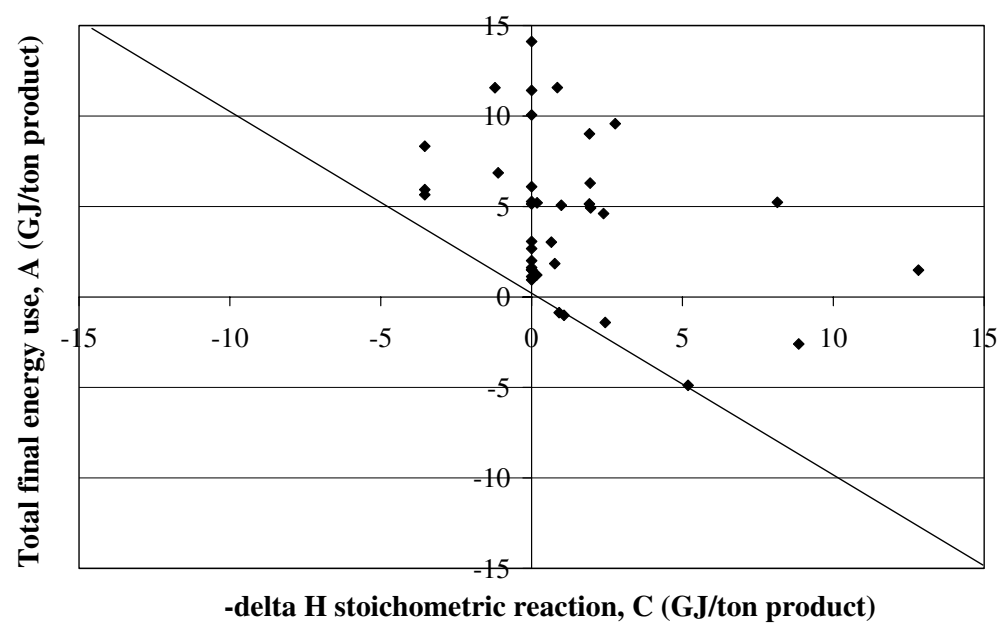

Fig. 5. Total final energy-use (A) as a function of stoichometric heat of reaction (C) for processes applied in The Netherlands.

ond type of energy recovery. The sum of total final energy-use and heat effect of reaction as given in Fig. 3 might therefore be overestimated.

A plot of the total final energy-use (indicator A) as a function of the stoichometric heat of reaction (indicator C) is given in Fig. 5. As explained in Section 1, an energetically ideal process would, if we neglect the quality of the energy involved, use an amount of energy opposite to the heat of reaction. The vertical distance between the data points and the diagonal line is therefore an indicator for the energy inefficiency of a process. It would require detailed energy and exergy analyses to show how the energy is lost within the process (e.g. in the form of low-temperature cooling-water), but in general these processes could be improved by optimization of waste-heat utilisation, by for example pinch analyses or heat pumps, the improvement of catalysts to improve the once-through yields in the reactor, the use of advanced separation techniques, etc. Without going into detail, it is clear from Fig. 5 that the potentials for improvement are substantial.

\section{5. $\mathrm{CO}_{2}$ emissions in the chemical industry}

We also analysed the $\mathrm{CO}_{2}$ emissions associated with the processes included. For The Netherlands, the total amount of $\mathrm{CO}_{2}$ emissions associated with the processes included is $20.4 \mathrm{Mt} \mathrm{CO}_{2}{ }^{8}$, which is more than $90 \%$ of the emissions in the chemical industry as reported in the National Inventory Report for The Netherlands [19]. The emissions are the sum of fuel use in olefin production (5.1 $\mathrm{Mt} \mathrm{CO}_{2}, 22 \%$ ), ammonia and methanol production (6.1 $\left.\mathrm{Mt} \mathrm{CO}_{2}, 30 \%\right)$, other fuel/electricity use (7.6 $\left.\mathrm{Mt} \mathrm{CO}_{2}, 37 \%\right)$ and carbon losses resulting from non-selectivity (1.6 $\mathrm{Mt} \mathrm{CO}_{2}, 11 \%$ ). Theses carbon losses from non-selectiv-

\footnotetext{
${ }^{8}$ For steam, we assumed an emission factor of 0.09 ton $\mathrm{CO}_{2}$ per GJ; for electricity, an emission factor of 0.15 ton $\mathrm{CO}_{2}$ per GJ.
} 
ity are estimated to be approximately $35 \mathrm{Mt} \mathrm{CO}_{2}$ worldwide. Since the stoichometric reactions all have closed carbon balances, this is at the same time the ultimate improvement potential with respect to selectivity improvements for the processes included. It should be noted that the total emissions might be overestimated since part of the off-specs is burnt under the regeneration of steam. In the approach chosen, these emissions are doublecounted.

\section{Discussion and conclusions}

In this paper, we showed that it is possible to do a bottom-up energy and $\mathrm{CO}_{2}$ emission analysis of the chemical sector that yields reasonable results compared with top-down estimates of energy use and $\mathrm{CO}_{2}$ emissions. We showed that production processes for 52 of the largest chemicals cover more than $70 \%$ of the fuel and feedstock use of the chemical sector and approximately $30 \%$ of the electricity use. The low coverage of electricity can be explained by the fact that some major electricity-consuming processes are excluded and by the fact that more downstream processes that are not included tend to be more electricity and less fuel intensive. The sum of total final energy-use and the overall heat effect of reaction of the processes included in the analysis is 7986 PJ worldwide, $1451 \mathrm{PJ}$ in Western Europe and $261 \mathrm{PJ}$ in The Netherlands. Steam cracking to produce olefins and steam reforming to produce ammonia and methanol cover approximately $50 \%$ of this total. With the exception of the endothermic steam cracking and chlorine production processes, most processes have an exothermic character and the overall exothermicity of the processes included is $1191 \mathrm{PJ}$ worldwide, which is equivalent to approximately $60 \%$ of the total final energy-used in these processes (see Fig. 3: electricity and fuel/steam use other processes). The processes were also compared with the ideal stoichometric reactions. This comparison showed that the total energy loss resulting from non-selectivity account for approximately $50 \%$ of the exothermicity in the processes ( $\sim 500 \mathrm{PJ}$ worldwide). These losses were also calculated for $\mathrm{CO}_{2}$ and were shown to be to $35 \mathrm{Mt} \mathrm{CO}_{2}$ worldwide, which is at the same time the ultimate improvement resulting from selectivity improvements. Losses resulting from non-selectivity can either be caused by over-oxidation of the feedstock, resulting in direct $\mathrm{CO}_{2}$ emissions (e.g. ethylene oxide), by the formation of fuelgrade by-products (off-specs) or by the discharge of carbon containing products into waste-water.

The results shown in this paper should be regarded as preliminary and will be refined further. We intend to improve the methodology used for this paper by

- Taking into account capacity utilisations less than $100 \%$ in cases where capacity data are used.

- Taking into account differences in energy efficiency between the regions included.

- Using more of the available information to distinguish between datasets for average and best available technologies, in order to further specify improvement potentials.

- Assessing the quality of the data-sources used.

- Determining the uncertainty ranges for as many processes as possible.

- Collecting more information for processes where only old sources were available.

- Further quantifying the various types (waste-water, off-specs) of carbon losses and the position of off-specs in the chemical industry. 


\section{References}

[1] Association of Plastics Manufacturers in Europe. Eco-profiles of the European plastics industry. Various reports on different types of plastics, prepared by Dr. I. Boustead. Brussels; 1993-2004.

[2] Joosten L. The industrial metabolism of plastics - analysis of material flows, energy consumptions and $\mathrm{CO}_{2}$ emissions in the lifecycle of plastics, PhD thesis. Utrecht: Utrecht University; 2001.

[3] Patel M. Cumulative energy-demand (CED) and cumulative $\mathrm{CO}_{2}$ emissions for products of the organic chemical industry. Energy 2003;28:721-40.

[4] Gielen DJ, Vos D, van Dril AWN. The petrochemical industry and its energy use, prospects for the Dutch energy intensive industry. Petten: Energy Res Centre Neth; 1996.

[5] Worrell E, Phylipsen D, Einstein D, Martin N. Energy use and energy intensity of the US Chemical Industry. Berkeley: Lawrence Berkeley National Laboratory, Energy Analysis Department, Environmental Energy Technologies Division; 2000.

[6] US Department of Energy, Office of Industrial Technologies. Energy and Environmental Profile of the US Chemical Industry. Washington; 2000.

[7] Organisation for Economic Cooperation and Development. OECD Environmental Outlook for the Chemicals Industry. Paris; 2001.

[8] European Commission, Joint Research Centre, Institute for Prospective Technological Studies. Reference document on best available techniques in the large-volume organic chemical industry. Seville; 2003.

[9] Tonkovich ALY, Gerber MA. The Top 50 commodity chemicals: Impact of catalytic process limitations on energy, environment and economics. Richland: Pacific Northwest Laboratory; 1995.

[10] Nieuwlaar E. ICARUS-4: Sector study for the chemical industry. Utrecht: Department of Science, Technology and Society, Utrecht University; 2001.

[11] Lange JP. Fuels and chemicals manufacturing - guidelines for understanding and minimizing the production costs. CATTECH 2001;5(2):82-95.

[12] Chauvel A, Lefebvre G. Petrochemical processes, technical and economic characteristics. Paris: Editions Technip; 1999.

[13] Hydrocarbon processing. Petrochemical processes 2003. Hydrocarbon processing 2003; 82(3): $72-124$.

[14] Struker A, Blok K. NEEDIS - Sectorstudie organische chemie. Utrecht: Ecofys Advies en Onderzoek; 1995.

[15] Weissermel K, Arpe HJ. Industrielle Organische Chemie, bedeutende Vor- und Zwischenprodukte. Weinheim: Wiley-VCH; 1998.

[16] Chemical Week. Various issues of Chemical Week; 1994-2003.

[17] International Energy Agency. Energy balances of OECD countries and energy balances of non-OECD countries (2002 edition). Paris; 2002.

[18] NEU- $\mathrm{CO}_{2}$ : Non-energy use and $\mathrm{CO}_{2}$ emissions, Project funded by the European Commission. Project website: $<$ http://www.chem.uu.nl/nws/www/nenergy/>.

[19] Olivier JGJ, Brandes LP, Peters JAHW, Coenen PWHG. Greenhouse-Gas Emissions in The Netherlands 1990-2001, National Inventory Report 2003, Bilthoven: Dutch Institute for Public Health and the Environment; 2003. 